\title{
A Contribution to the Embryology of the Liver and Vascular System in Man.
}

\section{BY}

N. W. INGALLS, M.D.

From the Anatomical Laboratory of Western Reserve University.

The present paper is supplementary to a more extensive article that appeared in the Arch. f. m. Anat., Bd. $70^{1}$, and extends those observations and introduces some new material derived from further study of the same embryo. The drawings and plates were made in the Anatomisches Institut in Freiburg last summer and the models worked up here during the past winter.

The structures modeled include the entire liver circulation, together with a part of the sinus venosus, the same with the hepatic tissue in situ, both models also showing that portion of the gut tract included within the limits of the models, and, in addition-appearing in but one plate-the lungs, all 100 times enlarged. These structures, excepting the lungs, extend over some six segments, the last five cervical and the first thoracic. The caudal limits are just above the point where the vitelline duct joins the intestine, the anastomosis between the two omphalomesenteric veins being almost exactly on the same level with the lower free border of the ventral mesentery. Cranially, the plane cuts the two horns of the sinus venosus a little above the point where the right horn opens into the right atrium, the spindle-shaped stomach, which is just beginning its torsion, is cut slightly above the middle. Certain unessential details present in the models have, for the sake of clearness, been omitted in the plates, and for the same reason the connection of the liver substance with the gut in Plate IV is not shown.

Plate I gives a ventral view of the model of the veins and gut tract without the liver, the latter having been severed from its connections just above the gall bladder by a cut passing obliquely downward and forward.

The smaller right umbilical vein is just beginning to form a connection with the liver veins by a few small vessels and continues craniad

${ }^{1}$ Ingalls. Beschrelbung eines menschlichen Embryos von $4.9 \mathrm{~mm}$. Arch. f. m. Anat., Bd. 70, 1907. 
in the lateral body wall, here much larger than the corresponding vein of the opposite side, and empties, after having increased considerably in size, in common with the right omphalo-mesenteric vein, into the right horn of the sinus venosus. The left umbilical vein, caudally somewhat larger than the right, pours most of its blood into the hepatic sinusoids through two huge branches, its original course in the body wall is represented by a slender vessel, very small in its caudal portion, but increasing in size as it ascends and emptying into the left horn of the sinus venosus, lateral to the left omphalo-mesenteric vein. Of the two omphalo-mesenteric veins the right is much larger and the two are connected ventral to the gut by a very fine cross anastomosis. From here they pass craniad and dorsad in the mesentery and break up into branches on either side of the gut (Plate II). The branches from the right vein are much the larger and reunite again to form the original trunk of the vein. The left rein breaks up into three branches which run almost directly craniad, the two ventral ones connecting with the cranial venosus ring while the dorsal branch in addition anastomoses by two channels with the branches of the vein of the opposite side besides connecting with one of the mesenteric veins; the other mesenteric vein uniting with a branch of the right omphalo-mesenteric vein. There thus results a plexus of veins, half encircling the gut just below the dorsal pancreas anlage, and into which plexus is poured the blood from four veins, two omphalo-mesenteric and two mesenteric veins. From this plexus there pass craniad two wide channels, one, smaller, on the left of the gut, the other, much larger, on the right, which divides into two vessels, the one the continuation of the right omphalo-mesenteric, the other uniting ventral to the gut, just above the connection of the gut with the liver, with the already mentioned channel of the left side. Or, in other words, the branches of the left omphalo-mesenteric vein unite in part to form the left caudal portion of the cranial venous ring while the remaining establish a communication with the opposite side; the branches of the right omphalo-mesenteric vein, after breaking up into some three branches and after having received the branches from the left side, unite again to form one huge blood channel, which divides again almost immediately into a larger external branch which continues craniad and is the proximal portion of the right omphalomesenteric vein, and a somewhat smaller internal branch, which passes around the gut to meet the ressel of the left side and so complete the ring. 
Thus is formed the second or cranial venous ring, which is far more highly developed than the caudal ring with which it shares in common the dorsal plexiform anastomosis. This cranial ring is in close relation with the gut tract, fitting in, as it were, into the angle formed ventrocranially by the gut and the connection of the liver with the same, dorsocaudally between the gut and the dorsal pancreas anlage; it is obliquely placed, its ventral surface looking not only caudal, but also toward the right. Ventrally this ring is in free communication with the liver sinusoids and the anastomoses between it and the left umbilical vein are especially free. The cranial half of this ring has a triangular shape, the apex extending upward in front of the future duodenum and is continued into a blood-vessel that ascends on the post surface of the liver, ventral to and very near the stomach. From this ascending channel, the ductus venosus, there are given off-or received-several small branches opposite the caudal half of the stomach (Plate II); these are the veins first described by Broman ${ }^{2}$ and to which he attributes so large a rôle during the early development of the stomach; but whether the blood in these few vessels is going to or coming from the stomach, we will not venture to say. It may very well be that the pressure in the ductus venosus, and consequently in these vessels, is, on account of its free connection with the left umbilical vein, higher than in the capillaries around the stomach. That they have, at this stage at least, much functional significance seems to us doubtful. The ductus venosus, just above the cranial limit of the liver tissue in the median line, bends sharply to the right, and, after receiving branches from the liver substance, pours its blood for the most part into the common termination of the right umbilical and right omphalo-mesenteric veins and in part into the latter. At the point where the ductus venosus bends to the right, it receives a communicating branch from the most proximal portion of the left omphalo-mesenteric vein. It is this ressel that later serves to convey the blood from the left lobe of the liver to the inferior cava. The proximal portion of the left omphalo-mesenteric vein still persists, receiving its blood from numerous large anastomosing channels which occupy the left lobe of the liver and which possess free anastomoses with the left umbilical vein and the cranial venous ring, but none with the left omphalo-mesenteric vein. The sinusoids of the left lobe are of slightly larger calibre than those of the right and at the same time somewhat less numerous.

'Broman, Ueber die Existenz eines bisher unbekannten Kreislaufes im menschlichen Magen. Anat. Anz., 1903. 
Viewed as a whole, the bulk of the blood passing through the liver enters it by way of the left umbilical vein and leaves by the right omphalo-mesenteric. The path of least resistance would be through the branches of the left umbilical vein to the left side of the cranial venous ring, across the ventral half of this to the left omphalo-mesenteric; such may well be the course of the blood, as the right omphalo-mesenteric, where it joins the right umbilical to empty into the sinus venosus, is several times larger than both omphalo-mesenteric veins combined and the tributaries that it receives directly from the liver would not account for its great size.

Further description of the conditions present does not seem necessary, and Plates I and II will render clear the above account and supply whatever of nonessentials have been omitted from the same.

The liver has at this stage the typical horseshoe shape, and when seen as a model without its vessel is quite compact and solid. Its ventral surface (Plate III) is in relation cranially with the horizontal portion of the sinus renosus and presents a corresponding slight concavity from which several veins open directly into the sinus venosus. The caudal half of the ventral surface is in relation with the dorsal wall of the pericardial cavity in the region occupied by the ventricular loop. This surface is more convex and characterized, particularly on the right side, by numerous small, irregular outgrowths of hepatic tissue. Numbers of small vessels are found on this surface, but it was often impossible to determine their connections. The lateral surfaces are much smoother, but the left lobe especially is deeply grooved by the numerous large vessels that have not yet been outgrown by liver cells. The concavity of the liver, $i$. e., the internal surfaces of each lobe and the dorsal aspect of the connecting mass, presents a smooth surface where appear but a few small vessels aside from the ventral half of the cranial venous ring which lies here closely applied to the liver tissue and from which ascends, upon the dorsal surface of the liver, the ductus venosus. The most caudal extent of the liver tissue is represented by several small processes which extend along the branches of the left umbilical vein or project free into the surrounding mesoderm; this is most marked to the left side of the median line. Not only is the left liver lobe smaller than the right, but relative to the number of blood-vessels there is less liver tissue here. In the upper half of the left lobe the large channels which represent the original left omphalo-mesenteric are entirely exposed on their external surface, internally, on the surface toward the gut, the liver tissue has 
extended farther and conceals these vessels almost entirely, reaching as far as the connection between the omphalo-mesenteric and the ductus venosus. In the right lobe the hepatic tissue reaches much further craniad, being in relation with the right umbilical at its termination. Only the dorso-lateral wall of the right omphalo-mesenteric. vein is more or less free from liver tissue, and above at one point is has been entirely encircled by it. It is on the internal aspect of the right lobe that the hepatic tissue reaches highest as a thin sheet closely applied to the inner wall of the right omphalo-mesenteric vein.

Taken as a whole and without regard to the veins, examination of the liver reveals the following points of interest. Viewed from above it is seen that the right lobe is much larger than the left and extends farther dorsad. In ventral view the right lobe also extends farther craniad, while the bulk of the liver tissue caudally is to the left of the median line. Viewed from either side, but especially marked when seen from the right side, it is found that the liver appears as a somewhat elongated mass, of which the long axis runs caudo-craniad. It will thus be seen that the trend of the liver tissue is the same as that of the blood poured into the hepatic sinusoids, and a line drawn from the point where the branches of the left umbilical vein enter the liver to the point where the right omphalo-mesenteric leaves it, while giving the point of entrance and exit of the bulk of the blood passing through the liver, will also represent the long axis of the mass of hepatic tissue.

For certain details not found here the reader is referred to the above cited description of the embryo.

I should like to call attention here to certain structures already but merely touched upon in the systematic description of the embryo (1) and to which it seems to me possible to give another interpretation. On page 524 of the article just referred to occurs this sentence and outside of which I have not considered the structure in question: "gerade wo dic Vena card. post. zur Bildung des Ductus Cuvieri sich stark ventralwärts biegt, empfängt sie einige grosse absteigende Zuflïsse." Fig. 11, page 522, illustrated the condition.

My attention was directed to the possible significance of these vessels by the work of Huntington and $\mathrm{McClure}^{3}$ on the early development of

'Huntington and McClure. The Anatomy and Development of the Jugular Lymph Sacs in the Domestic cat (Felis domestica). The Anatomical Record, Vol. II. 
the lymphatic system in the cat, and I have been led to look upon them as the first anlage, or earliest forerunners, perhaps, of the lymphatic ystem in man.

Figs. 1 and 2 are reconstructions of the right and left sides respectively, showing the anterior and posterior cardinals, the duct of Cuvier and the vessels already mentioned. These structures extend over five segments, the last occipital and the first four cervical. Just dorsal to the most proximal portion of the superior cardinal and emptying in

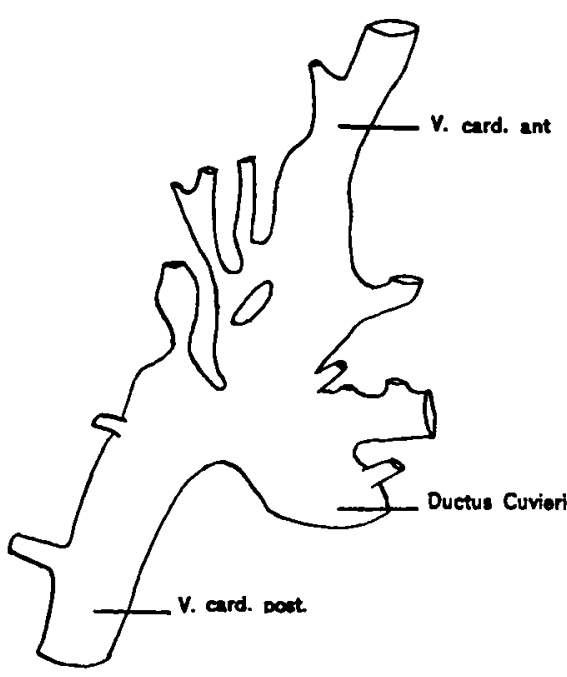

Fig. 1

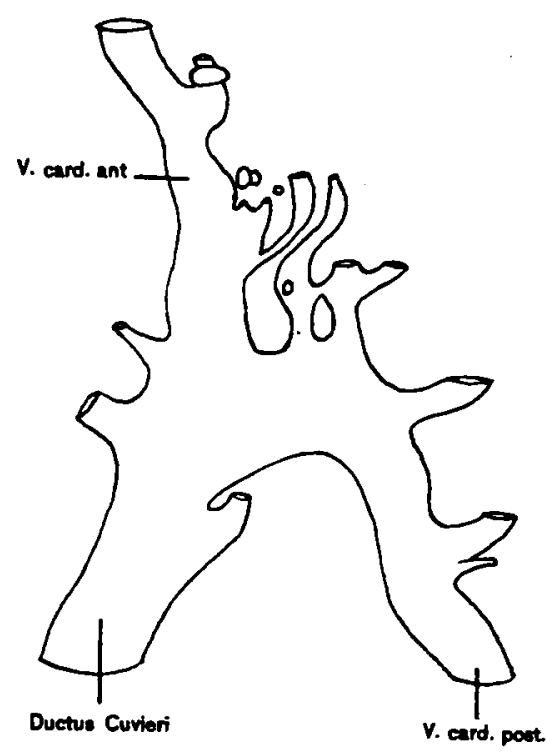

FIG. 2

part into this vesel and in part into the posterior cardinal as it bends forward to unite with the superior cardinal are found a number of small vessels, rather more numerous on the left side. These lie for the most part in a plane placed almost sagitally-the more dorsal vessels being slightly nearer the median line-lateral and somewhat ventral to the dorsal aortæ and ventral or even internal to the ventral border of the myotomes. Most of these vessels have a connection with one of the cardinal veins, but others have apparently no such connections. These structures bear no small resemblance to those pictured by Huntington, ${ }^{4}$

'Huntington. The Genetic Interpretation of the Development of the Mammalian Lymphatic System. The Anatomical Record, Vol. II. 
Fig. 6, differing from those largely on account of the absence of any fenestration. The stage of the embryo from which his Fig. 6 is taken is, however, much older than that here described. It is true that the beginnings of the lymphatic system have been described in other animals at a stage more advanced than that of this embryo, but the findings here, almost exactly the same topographically, have seemed sufficient to warrant the view that these vessels are veno-lymphatics. 


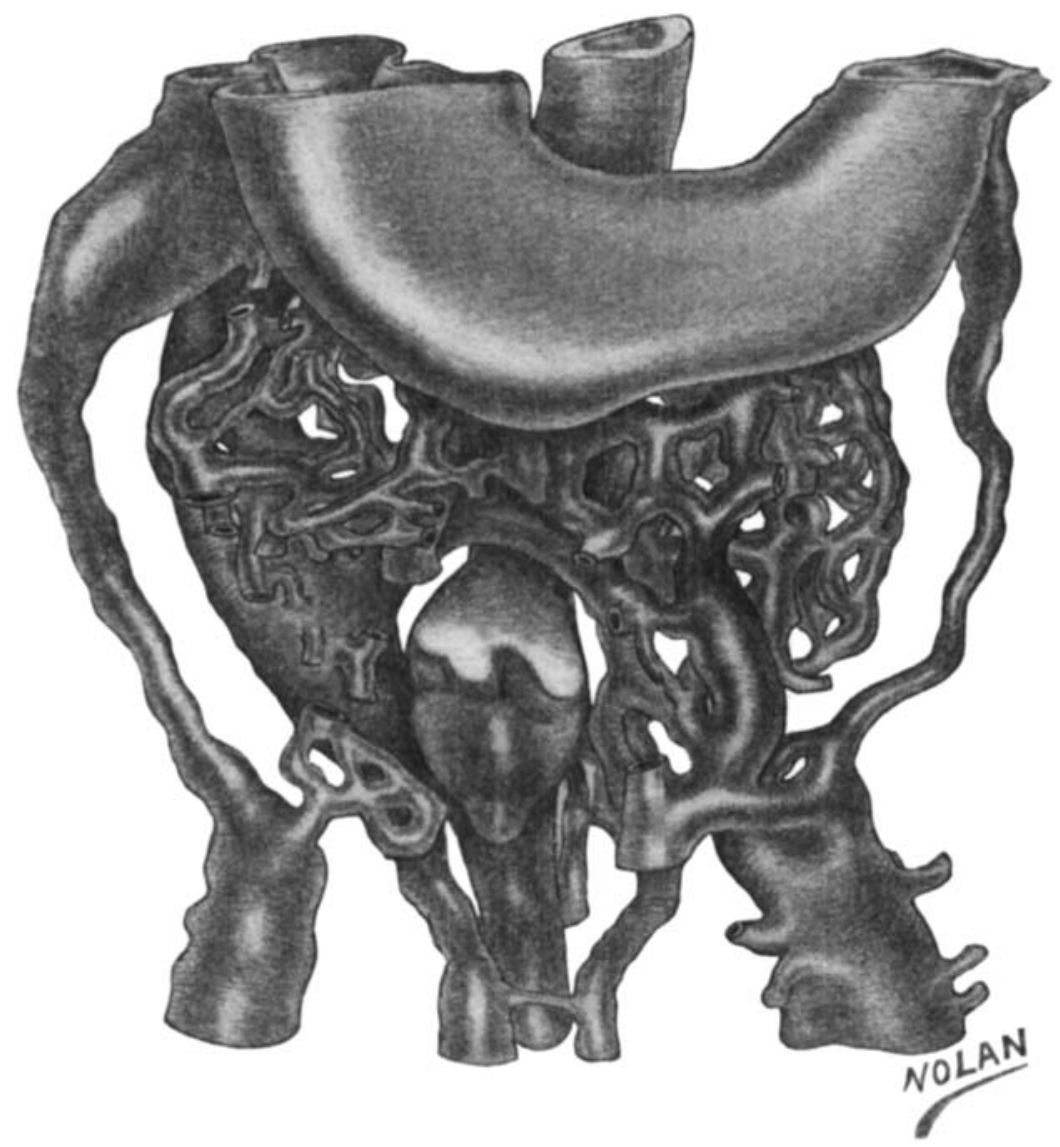

PIATE I.-Model of veins, ventral view, the connertion of the liver and gut has been severed just above the gall-bludder anluge. Just above this is seen the veutral half of the cranial venous ring in connection with both ompbulo-mesenteric, and the left umbilial reins. $X 100$. 


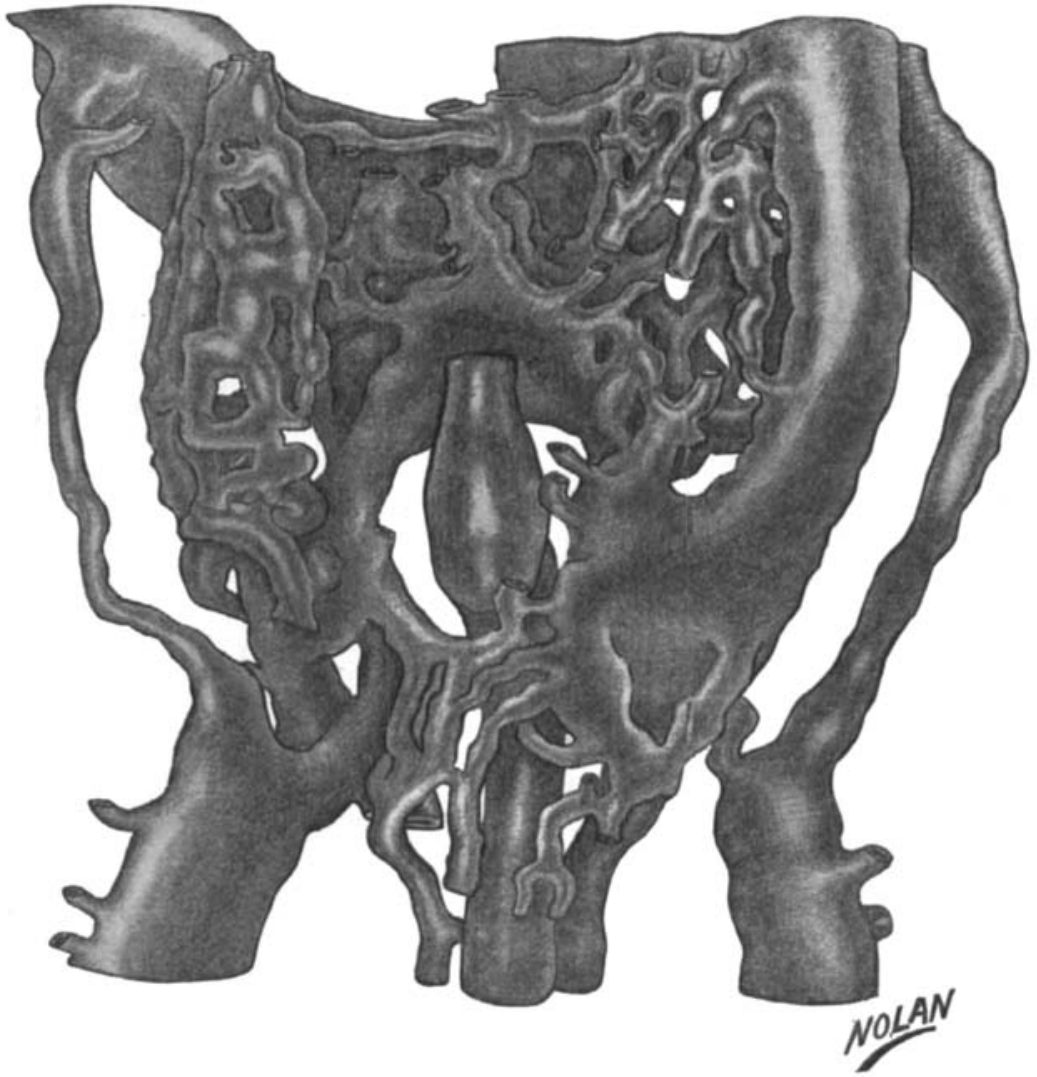

Plate II.-Dorsal view of same model, the stomnch has been remored, thereby exposing the ductus venosus and the veins of Broman. $\times 100$. 


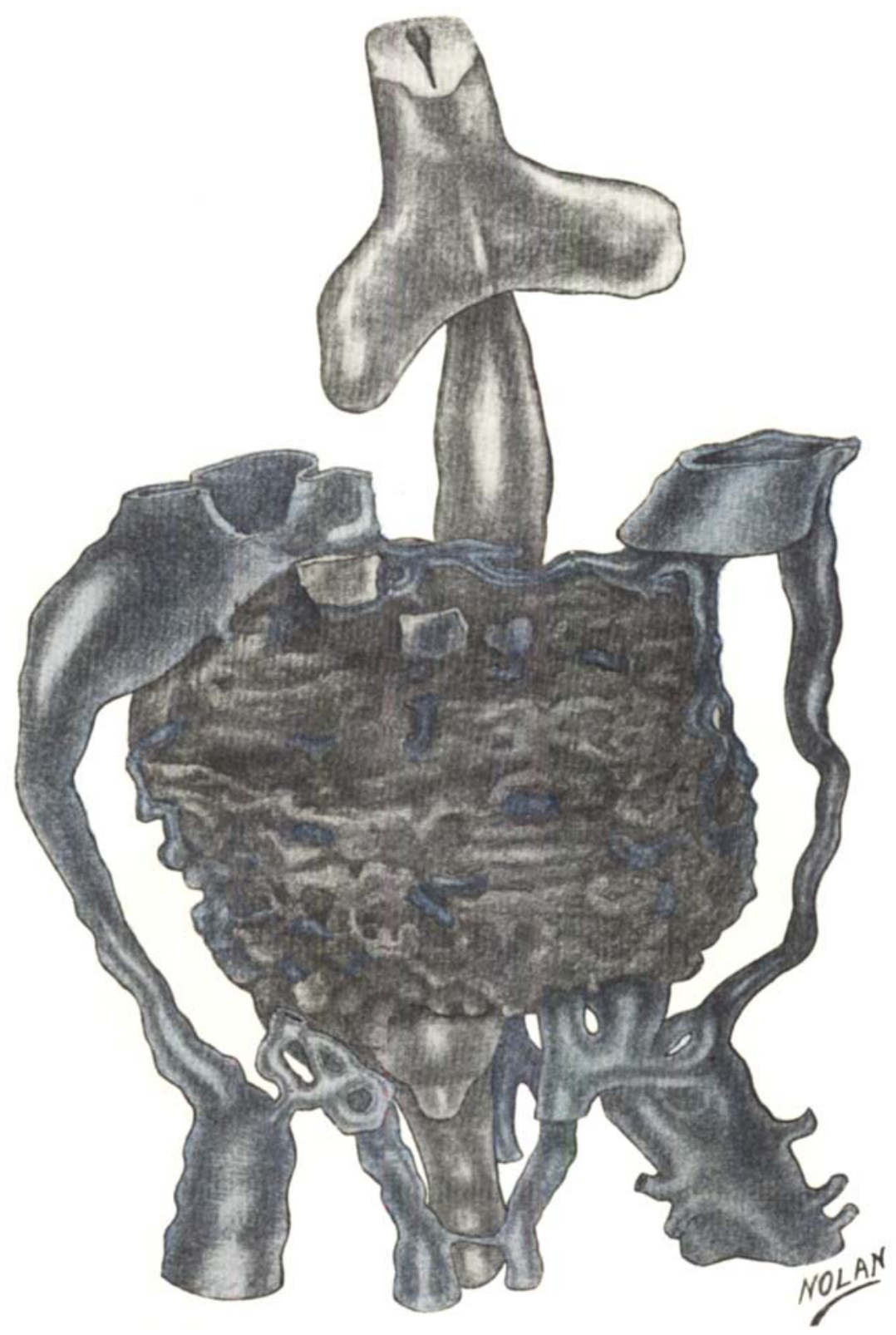

Prate I1I.-Liver and reins. Lung anlage above. Immediately below the terminal horizontal portion of the ductus venosus appear three portions of the posterior wall of the sinus renosus where empty veins coming from the liver. Below the liver is seen the gall-bladder anlage and beneath this the ventral pancreas. $\times 100$. 


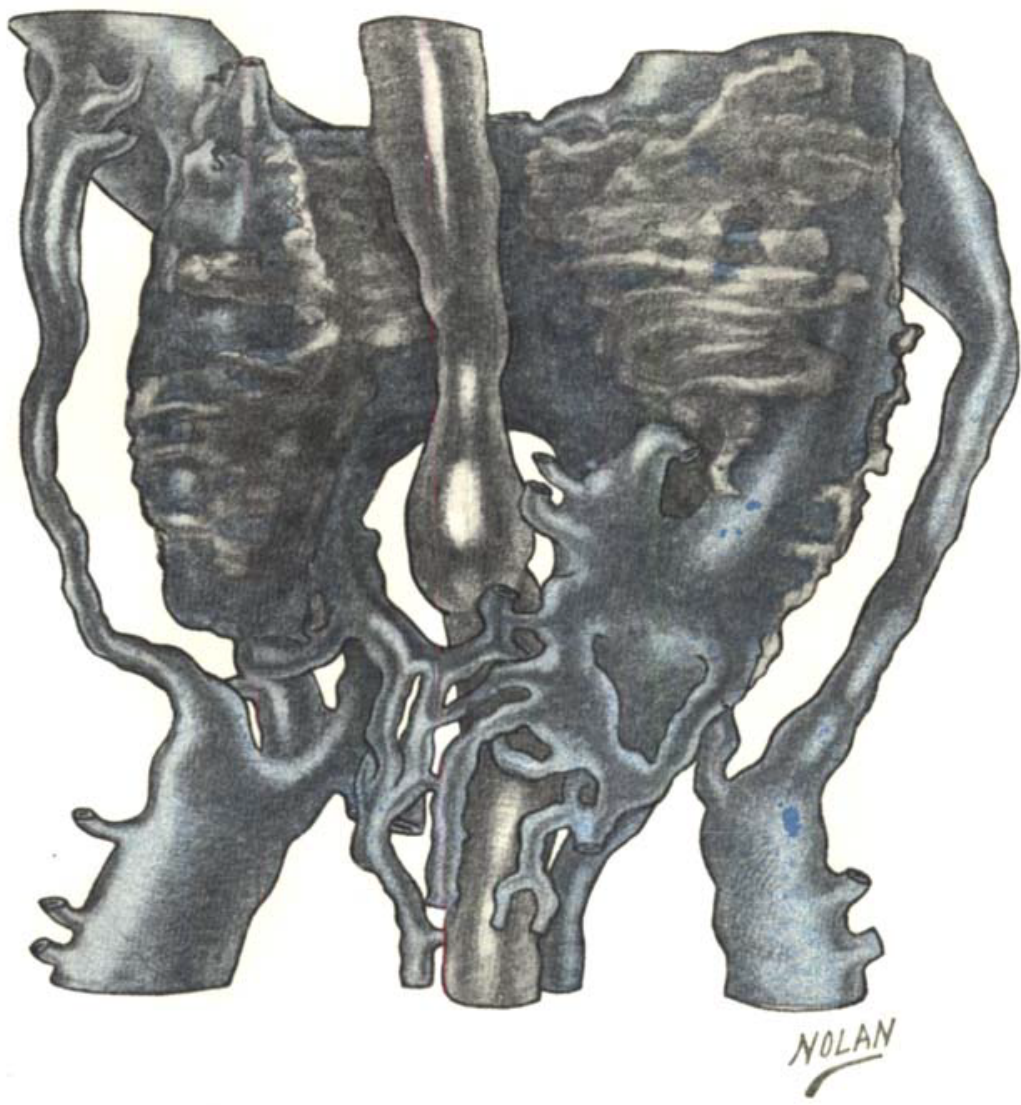

I'Jate IV.-Dorsal riew of same. To the right of the stomandh and partly hididen hy it is seen the ductus venosus: the connestion of liver and gut hass been onitted for the sake of (-Jenrness: just ntwove the dorsnl plexitorm mastomosis is the dorsall muncreas. $\times 11 \%$. 